\title{
Beneficial effects of combined olive oil ingestion and acute exercise on postprandial TAG concentrations in healthy young women
}

\author{
Chihoko Sasahara $^{1 *}$, Stephen F. Burns ${ }^{2}$, Masashi Miyashita ${ }^{3}$ and David J. Stensel ${ }^{4}$ \\ ${ }^{1}$ Department of Education, School of Education, Meisei University, Tokyo, Japan \\ ${ }^{2}$ Physical Education and Sports Science Academic Group, Nanyang Technological University, Singapore, Singapore \\ ${ }^{3}$ Faculty of Sports Sciences, Waseda University, Tokyo, Japan \\ ${ }^{4}$ School of Sport, Exercise and Health Sciences, Loughborough University, Loughborough, Leicestershire, UK \\ (Submitted 13 October 2011 - Final revision received 7 December 2011 - Accepted 9 December 2011 - First published online 23 January 2012)
}

\section{Abstract}

Foods high in monounsaturated fat, such as olive oil, and endurance exercise are both known to independently reduce postprandial TAG concentrations. We examined the combined effects of exercise and dietary fat composition on postprandial TAG concentrations in nine healthy pre-menopausal females (age 26.8 (SD 3.3) years, BMI $22 \cdot 3(\mathrm{sD} 2 \cdot 0) \mathrm{kg} / \mathrm{m}^{2}$ ). Each participant completed four, $2 \mathrm{~d}$ trials in a randomised order: (1) butter-no exercise, (2) olive oil-no exercise, (3) butter-exercise, (4) olive oil-exercise. On day 1 of the exercise trials, participants walked or ran on a treadmill for $60 \mathrm{~min}$. On the no-exercise trials, participants rested on day 1 . On day 2 of each trial, participants rested and consumed an olive oil meal (saturated fat $15 \%$ and unsaturated fat $85 \%$ ) or a butter meal (saturated fat $71 \%$ and unsaturated fat 29\%) for breakfast. Venous blood samples were obtained in the fasted state and for $6 \mathrm{~h}$ postprandially on day 2 . A significant main effect on physical activity (exercise or control) was obtained for plasma TAG concentration (three-way ANOVA, $P=0.043$ ), and the total area under the concentration $v$. time curve for TAG was $26 \%$ lower on the olive oil-exercise trial (4.40 (sD $0 \cdot 40) \mathrm{mmol} \times 6 \mathrm{~h} / \mathrm{l})$ than the butter-no exercise trial $(5.91(\mathrm{sD} 1.01) \mathrm{mmol} \times 6 \mathrm{~h} / \mathrm{l})$ (one-way ANOVA, $P=0 \cdot 029)$. These findings suggest that the combination of exercise and a preference for monounsaturated dietary fat intake in the form of olive oil may be most beneficial for reducing postprandial TAG concentrations.

Key words: Monounsaturated fat: Saturated fat: Aerobic exercise: Postprandial lipaemia

Olive oil is the primary source of fat in Mediterranean diets and is associated with a lower rate of mortality for CHD and $\mathrm{CVD}^{(1-3)}$. Conversely, increased non-fasting TAG, also known as postprandial lipaemia, is an independent risk factor for myocardial infarction, cardiovascular events and death in both men and women ${ }^{(4,5)}$. Olive oil consumption may reduce postprandial lipaemia because of the high MUFA content of the oil. There is conflicting evidence, however, regarding the acute effect of meals high in MUFA on postprandial TAG concentrations. One group $^{(6,7)}$ found lower plasma TAG and lower chylomicron-rich TAG concentrations in healthy people and overweight individuals with type 2 diabetes after MUFA meals compared with meals high in SFA. Conversely, other studies have shown that meals high in SFA induce lower postprandial serum or chylomicron TAG concentrations ${ }^{(8)}$, or that there are no differences between meals of different fat content ${ }^{(9,10)}$. Such discrepancies may be partly explained by differences in the amount of fat consumed, the overall composition of the test meal and the participants involved.

A sex dimorphism exists in postprandial TAG metabolism. Males show higher plasma TAG responses to a high-fat meal than females ${ }^{(11)}$. Increased abdominal visceral adipose tissue accumulation in males makes an important contribution to the sexual dimorphism in postprandial TAG metabolism ${ }^{(12)}$. However, limited evidence is available on postprandial TAG metabolism in young women. Koutsari et al. ${ }^{(13)}$ observed greater TAG concentrations after MUFA meals in young males while identical TAG response patterns were observed in females after meals high in MUFA $v$. SFA. Menopausal status is also known to influence postprandial lipaemia, with higher values observed in postmenopausal women compared with pre-menopausal women ${ }^{(14)}$.

Exercise is an effective strategy for reducing postprandial TAG concentrations ${ }^{(15)}$. Evidence suggests that the total energy expenditure of physical activity determines the size

Abbreviations: Butter-Con, butter-no exercise trial; Butter-Ex, butter-exercise trial; HDL-C, HDL-cholesterol; HOMA1-IR, homeostasis model insulin resistance; Olive-Con, olive oil-no exercise trial; Olive-Ex, olive oil-exercise trial.

*Corresponding author: Dr C. Sasahara, fax +81 42591 9240, email sasahara@ge.meisei-u.ac.jp 
of any reduction in postprandial $\mathrm{TAG}^{(15-17)}$, and activity must be performed frequently for continued benefits ${ }^{(18-20)}$. Whether meals, and more specifically dietary fat composition, affect exercise-induced reductions in TAG has not been investigated. Exercise offsets increases in TAG seen with high-carbohydrate diets ${ }^{(21-23)}$ but only to the same extent as low-carbohydrate diets taken without exercise. Whether varying the fat composition of a meal or diet influences exercise-induced reductions in TAG is uncertain. There is some evidence that females tend to preserve body fat in response to aerobic exercise, by more accurately matching energy intake with energy expenditure than males ${ }^{(24,25)}$. Thus, women may need to combine exercise with a healthy diet to receive the full benefit of any TAG-lowering effect. This may be an attractive strategy for women who wish to incorporate daily exercise and healthy eating into their life.

The purpose of the present study, therefore, was to examine the combined effects of exercise and fat composition of meals on postprandial TAG concentrations in healthy young women.

\section{Methods}

\section{Participants}

A total of nine healthy, normally active, pre-menopausal women aged 23-33 years participated in the present study. The study was conducted according to the guidelines laid down in the Declaration of Helsinki and all procedures involving human participants were approved by the Loughborough University's Ethical Advisory Committee. Written informed consent was obtained from all participants. Participants were recruited only if they met the following criteria: non-smoking; no known history of CVD; BMI $<30 \mathrm{~kg} / \mathrm{m}^{2}$; resting arterial blood pressure $<140 / 90 \mathrm{mmHg}$; not taking any medication known to affect lipid or cardiovascular metabolism. Of the nine participants, one was taking the oral contraceptive pill, and all participants had a regular menstrual cycle. The physical characteristics of the participants were as follows: age $26 \cdot 8$ (SD 3.3) years; height 1.62 (SD 0.04$) \mathrm{m}$; body mass 58.6 (SD 4.5 ) kg; BMI 22.3 (SD $2 \cdot 0$ ) $\mathrm{kg} / \mathrm{m}^{2}$; body fat 22.5 (SD 3.2 ) \%.

\section{Preliminary tests}

Anthropometry. Stature and body mass were determined using standard methods. Skinfold thickness was measured at three sites (triceps, quadriceps and suprailiac) using callipers (John Bull; British Indicators Limited). Body density was calculated using a three-site formula ${ }^{(26)}$, and then body fat percentage estimated using the Siri equation ${ }^{(27)}$.

Exercise tests. Participants performed two preliminary exercise tests on a motorised treadmill. In the first test, the relationship between steady-state oxygen uptake and treadmill speed was established using a 16 min submaximal test. In the second test, maximum oxygen uptake was directly determined using an incremental uphill protocol at a constant speed until voluntary fatigue ${ }^{(28)}$. Expired-air samples were collected during both tests using Douglas bags (Plysu
Protection Systems). Heart rate was monitored using shortrange telemetry (Polar A3; Polar Electro Inc.). Ratings of perceived exertion were periodically assessed ${ }^{(29)}$. The speed needed to elicit $60 \%$ of maximum oxygen uptake was then interpolated on an individual basis.

Control of diet and exercise. For $2 \mathrm{~d}$ before each main trial, participants were asked to refrain from physical activity except gentle walking for personal transportation over short distances. Participants weighed and recorded all food and drink they consumed for $2 \mathrm{~d}$ before their first main trial. They then consumed an identical diet for $2 \mathrm{~d}$ before subsequent trials. Participants refrained from alcohol during these periods.

\section{Main trials}

Each participant underwent four, $2 \mathrm{~d}$ trials in a randomised order: (1) olive oil-exercise trial (Olive-Ex), (2) butterexercise trial (Butter-Ex), (3) olive oil-no exercise trial (Olive-Con), (4) butter-no exercise trial (Butter-Con). The interval between the trials was at least 1 week. Since the postprandial TAG response is influenced by the phase of the menstrual cycle $^{(30)}$, each main trial was conducted during the follicular phase.

A schematic representation of the study protocol is shown in Fig. 1. For the exercise trials (Olive-Ex and Butter-Ex), participants walked/ran on a treadmill for $60 \mathrm{~min}$ at $60 \%$ of maximum oxygen uptake on the afternoon of day 1 . For the control trials (Olive-Con and Butter-Con), participants rested on day 1 . On the morning of day 2 in each trial, participants reported to the laboratory at 08.00 hours after a $10 \mathrm{~h}$ overnight fast. A cannula (Venflon; Becton Dickinson) was inserted into an antecubital or forearm vein and a baseline blood sample was taken. Participants then consumed a test meal. This meal comprised garlic toast and tomato soup and was given according to body mass ( $65 \mathrm{~kJ} / \mathrm{kg}$ body mass). The macronutrient composition of the meal was $55 \%$ fat, $39 \%$ carbohydrate and $6 \%$ protein. The fat in this meal was supplied from either olive oil (SFA: 15\%; MUFA: 76\%; polyunsaturated fat, PUFA: 9\%) or butter (SFA: 71\%; MUFA: 26\%; PUFA: 3\%). All participants consumed the meal within $20 \mathrm{~min}$. A clock was started with the first bite of this meal (time 0). Further blood samples were collected at hourly intervals for $6 \mathrm{~h}$ for determining the concentrations of plasma TAG, HDL-cholesterol (HDL-C) and glucose, and for $4 \mathrm{~h}$ for insulin. Additional samples for glucose and insulin were obtained at 0.5 and $0.75 \mathrm{~h}$. Water was available ad libitum during the first trial; the volume ingested was recorded and replicated in the other three trials. Participants rested (reading, working and watching television) throughout the observation period and were always lying in a supine position for at least $5 \mathrm{~min}$ before each blood sample was taken.

\section{Analytical methods}

For plasma TAG, glucose, insulin and HDL-C measurements, venous blood samples were collected into pre-cooled $9 \mathrm{ml}$ potassium-EDTA monovettes (Sarstedt) which were kept on ice until centrifugation. Plasma was separated within $15 \mathrm{~min}$ 

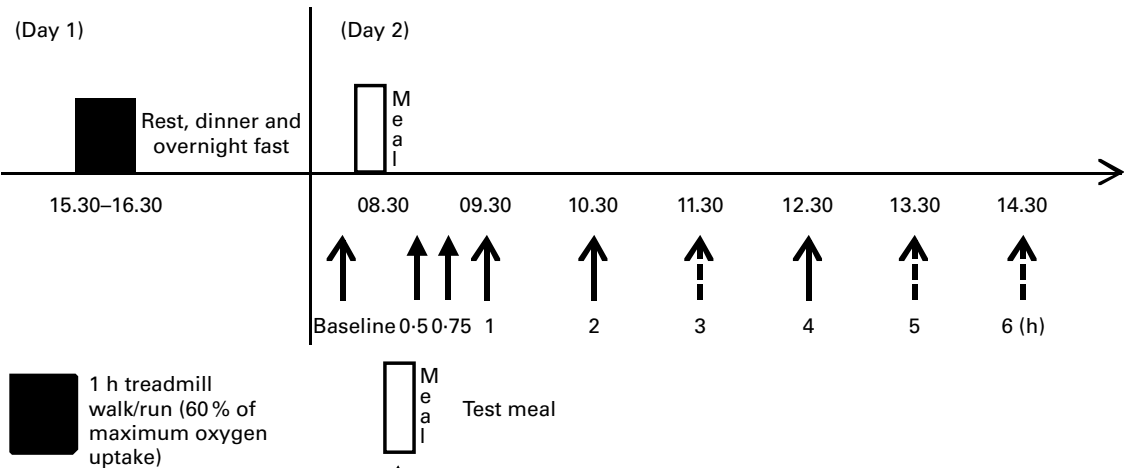
uptake

A Blood sample (TAG, glucose, insulin, and HDL-C)

Controltrial: participants rested on day 1

Blood sample (TAG, glucose, and HDL-C)

4 Blood sample (glucose and insulin)

Fig. 1. Schematic representation of the study protocol. HDL-C, HDL-cholesterol.

of collection, divided into aliquots and stored at $-80^{\circ} \mathrm{C}$. Plasma samples were analysed (within 6 months of collection) for TAG, glucose and HDL-C (Randox Laboratories Limited) by enzymatic colorimetric methods with the use of a centrifugal analyser (Cobas Mira Plus; Roche). Plasma insulin concentration was determined using a solid-phase ${ }^{125}$ I RIA from a commercially available kit (MP Biomedicals). Radioactivity was measured using an automated $\boldsymbol{\gamma}$-counting system (Cobra II; Packard Instruments). The within-batch CV for the assays were as follows: TAG $1.3 \%$, glucose $0.8 \%$, insulin $8.9 \%$, HDL-C $2 \cdot 1 \%$. To eliminate inter-assay variation, samples from all four trials for each participant were analysed in the same batch. Hb concentration and haematocrit were measured at baseline and at the end of the observation period to estimate changes in plasma volume ${ }^{(31)}$. As a surrogate fasting measure of insulin resistance, homeostasis model insulin resistance (HOMA1-IR) was calculated using the formula ${ }^{(32)}$ :

$$
\begin{aligned}
& \text { HOMA1-IR }=[(\text { fasting insulin }(\mu \mathrm{U} / \mathrm{ml})) \\
& \times(\text { fasting glucose }(\mathrm{mmol} / \mathrm{l}))] / 22 \cdot 5
\end{aligned}
$$

\section{Statistical analysis}

Data were analysed using statistical software (IBM SPSS version 18.0; SPSS, Inc.). Area under the curve values for plasma concentrations over time were calculated using the trapezium rule. The incremental area under the curve was calculated using the same method after correcting for baseline concentrations. Student's $t$ tests for correlated data were used to compare exercise responses. Body weight, fasting values, area under the curve values, peak postprandial TAG values and HOMA1-IR were compared among the trials using one-way ANOVA with repeated measures. Multiple $t$ tests with Bonferroni adjustment (significance values multiplied by the number of $t$ test comparisons performed) were used to determine where significant differences occurred, which were identified by one-way ANOVA. Three-way ANOVA with repeated measures was used to determine the effect of food (olive oil or butter), physical activity (exercise or control) and postprandial interval (from 0 to $6 \mathrm{~h}$ ) on concentrations of TAG, glucose, insulin (from 0 to $4 \mathrm{~h}$ ) and HDL-C. Where appropriate post hoc comparisons for three-way ANOVA were made using simple main effect tests. Relationships between variables were evaluated using Pearson's productmoment correlation coefficient. Significance was accepted at the 5\% level. Results are presented as means and standard deviations unless otherwise stated.

\section{Results}

\section{Exercise session}

There were no differences between the two exercise trials for estimated gross energy expenditure during exercise (OliveEx: $1.95(\mathrm{SD} 0.35) \mathrm{MJ} / \mathrm{h}(465(\mathrm{sD} 84) \mathrm{kcal} / \mathrm{h}) ;$ Butter-Ex: $2 \cdot 05$ (SD 0.34$) \mathrm{MJ} / \mathrm{h}(491(\mathrm{SD} 82) \mathrm{kcal} / \mathrm{h}), P=0 \cdot 204)$, exercise intensity (Olive-Ex: 56.7 (SD 6.9)\% of maximum oxygen uptake; Butter-Ex: 59.5 (SD 3.0)\% of maximum oxygen uptake, $P=0 \cdot 160$ ), heart rate (Olive-Ex: 150 (sD 8) beats/min; ButterEx: 153 (SD 12) beats/min, $P=0 \cdot 491$ ) or ratings of perceived exertion (Olive-Ex: 12 (SD 1); Butter-Ex: 12 (SD 1), $P=1 \cdot 000$ ).

\section{Body mass and plasma concentrations in the fasted state}

Participants maintained a stable body mass throughout the study. No significant difference was observed among the trials for body mass (Olive-Ex: 58.4 (SD 4.7) kg; Butter-Ex: $59 \cdot 1$ (SD 5.6) kg; Olive-Con: $59 \cdot 8$ (SD 5.1) kg; Butter-Con: 58.9 $(\mathrm{SD} 5 \cdot 1) \mathrm{kg}, P=0 \cdot 137)$. Plasma concentrations in the fasted state are shown in Table 1 . There were no differences in fasting concentrations of plasma TAG, insulin, glucose and HDL-C among the trials. No difference was observed among the trials in HOMA1-IR (Olive-Ex: 1.55 (SD 0.44); Butter-Ex: 1.47 (sD 0.43); Olive-Con: 1.50 (sD 0.42); Butter-Con: 1.65 (sD 0.69), $P=0.357$ ). 
Table 1. Fasting plasma concentrations of TAG, insulin, glucose and HDL-cholesterol

(Mean values and standard deviations, $n$ 9)

\begin{tabular}{|c|c|c|c|c|c|c|c|c|c|}
\hline & \multicolumn{2}{|c|}{ Butter-Con } & \multicolumn{2}{|c|}{ Olive-Con } & \multicolumn{2}{|c|}{ Butter-Ex } & \multicolumn{2}{|c|}{ Olive-Ex } & \multirow{2}{*}{$\begin{array}{c}P \text { (one-way } \\
\text { ANOVA) }\end{array}$} \\
\hline & Mean & SD & Mean & SD & Mean & SD & Mean & SD & \\
\hline Insulin $(\mathrm{pmol} / \mathrm{l})^{\star}$ & 53 & 21 & 48 & 13 & 47 & 13 & 51 & 14 & 0.360 \\
\hline Glucose $(\mathrm{mmol} / \mathrm{l})$ & $4 \cdot 88$ & 0.34 & $4 \cdot 85$ & 0.39 & $4 \cdot 85$ & 0.36 & $4 \cdot 81$ & 0.39 & 0.724 \\
\hline $\mathrm{HDL}-\mathrm{C}(\mathrm{mmol} / \mathrm{l})$ & 1.53 & 0.20 & 1.59 & 0.24 & $1 \cdot 51$ & 0.11 & 1.45 & 0.36 & 0.596 \\
\hline
\end{tabular}

\section{Plasma concentrations in the postprandial state}

Changes in plasma volume over the period of observation did not differ among the trials $(P=0 \cdot 191)$. No adjustments were made, therefore, to the measured concentrations of plasma constituents.

Plasma TAG responses are shown in Fig. 2. Three-way ANOVA with repeated measures showed a significant main effect of physical activity $\left(F_{(1)}=5.738, P=0.043\right)$ and a main effect of postprandial interval $\left(F_{(6)}=5.738, P<0.001\right)$ for plasma TAG concentrations. Significant interactions between food and the postprandial interval $\left(F_{(6)}=5.301, P<0.001\right)$ and between physical activity and the postprandial interval $\left.{ }^{(3.532)}=2.967, P=0.042\right)$ were found. Simple main effect tests revealed that TAG concentrations were lower on the olive oil trials than on the butter trials 3 and $4 \mathrm{~h}$ after consumption of the meal, and lower on the exercise trials than on the control trials 1,3 and $4 \mathrm{~h}$ after consumption of the meal. Peak postprandial TAG values tended to be lower on the exercise trials (Olive-Ex: 1.01 (sD 0.13) mmol/1; Butter-Ex: 1.09 (sD $0 \cdot 23) \mathrm{mmol} / \mathrm{l}$ ) than on the control trials (Olive-Con: 1.33 ( $\mathrm{sD}$ $0.48) \mathrm{mmol} / \mathrm{l}$; Butter-Con: 1.39 (sD 0.33$) \mathrm{mmol} / \mathrm{l})(P=0.059)$. The total and incremental area under the curve values for plasma TAG concentration $v$. time are given in Table 2 . The Olive-Ex trial induced the lowest TAG area under the curve value among the four trials. The total and incremental area under the curve values on this trial were 26 and $48 \%$ lower respectively than those on the Butter-Con trial.

Plasma insulin concentrations (Fig. 3(a)) rose steeply after the meal and then gradually decreased to baseline concentrations on all trials: main effect of postprandial interval $\left(F_{(5)}=3.973, P=0.005\right)$. There were no trial differences or trial $\times$ time interactions for plasma insulin concentrations. Plasma glucose concentrations (Fig. 3(b)) showed a steep rise and fall in the early postprandial period followed by a slow decrease to baseline: main effect of postprandial interval $\left(F_{(3.079)}=11.547, P<0.001\right)$. A significant main effect of food was found for plasma glucose concentrations $\left(F_{(1)}=8.8893\right.$, $P=0.018$ ), indicating higher values on the butter trials than on the olive oil trials. The total area under the concentration $v$. time curves for plasma insulin and glucose are shown in Table 2. There were no differences in the total area under the curve values for insulin and glucose among the trials. Insulin area under the curve and TAG area under the curve were significantly correlated in the Butter-Con trial ( $r$ 0.674,
$P<0.046)$ but not in the other trials. Plasma HDL-C did not differ among the trials or over time.

\section{Discussion}

To our knowledge, the present study is the first to examine the combined effects of exercise and dietary fat composition on postprandial TAG concentrations. The main finding is that a combination of a high-fat meal containing olive oil, high in MUFA, and exercise taken the previous day reduces postprandial plasma TAG concentrations in young women. The present findings suggest that for young women to obtain optimal reductions in postprandial lipaemia both dietary modification and increases in physical activity are necessary.

We found no overall difference in postprandial TAG responses between the olive oil meal and the butter meal

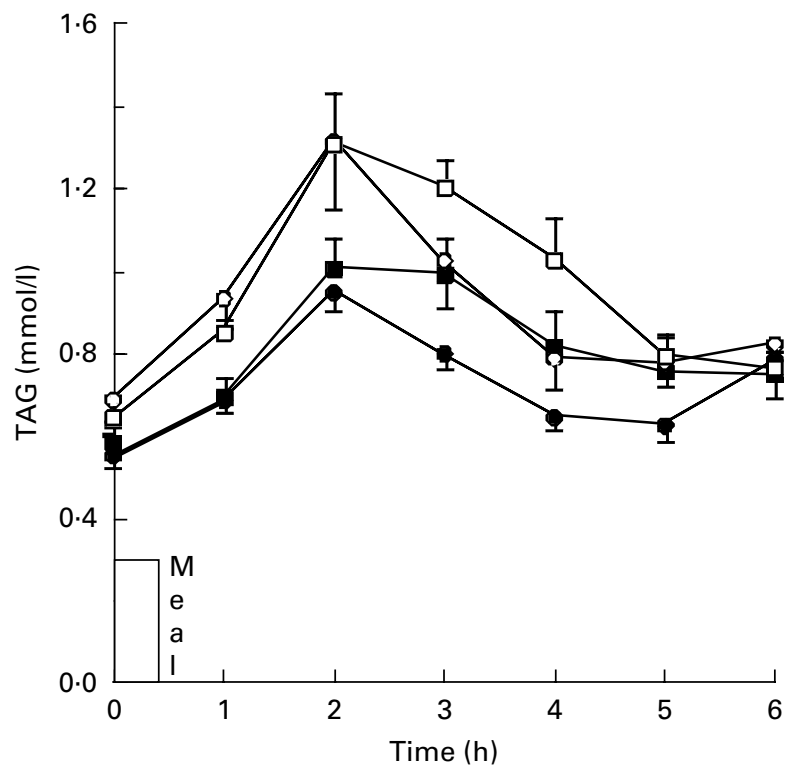

Fig. 2. Fasting and postprandial plasma TAG concentrations in olive oilexercise trial $(--)$, butter-exercise trial (- - ), olive oil-no exercise trial $(-\circ)$, butter-no exercise trial $(-\square-)$. Values are means $(n 9)$, with standard errors represented by vertical bars. Main effect of physical activity $\left(F_{(1)}=5.738, \quad P=0.043\right)$ and main effect of postprandial interval $\left(F_{(6)}=5.738, P<0.001\right)$. Simple main effect tests revealed that TAG concentrations were lower on the olive oil trials than on the butter trials $3 \mathrm{~h}$ $(P=0.027)$ and $4 \mathrm{~h}(P=0.022)$ and lower on the exercise trials than on control trials $1 \mathrm{~h}(P=0.008), 3 \mathrm{~h}(P=0.040)$ and $4 \mathrm{~h}(P=0.012)$ after consumption of the meal. 
Table 2. Total area under the concentration $v$. time curves for plasma TAG, insulin and glucose

(Mean values and standard deviations, $n$ 9)

\begin{tabular}{|c|c|c|c|c|c|c|c|c|c|}
\hline & \multicolumn{2}{|c|}{ Butter-Con } & \multicolumn{2}{|c|}{ Olive-Con } & \multicolumn{2}{|c|}{ Butter-Ex } & \multicolumn{2}{|c|}{ Olive-Ex } & \multirow{2}{*}{$\begin{array}{c}P \text { (one-way } \\
\text { ANOVA) }\end{array}$} \\
\hline & Mean & SD & Mean & SD & Mean & SD & Mean & SD & \\
\hline Total TAG $(\mathrm{mmol} \times 6 \mathrm{~h} / \mathrm{l})$ & 5.91 & 1.01 & $5 \cdot 62$ & 1.26 & 4.95 & $1 \cdot 18$ & 4.40 & 0.40 & $0.029^{*}$ \\
\hline Incremental TAG $(\mathrm{mmol} \times 6 \mathrm{~h} / \mathrm{l})$ & $2 \cdot 10$ & 1.30 & 1.55 & 0.98 & 1.46 & 0.91 & $1 \cdot 10$ & 0.47 & $0.033 \dagger$ \\
\hline Total insulin $(\mathrm{pmol} \times 4 \mathrm{~h} / \mathrm{l}) \ddagger$ & 1939 & 2304 & 1080 & 1219 & 1536 & 2525 & 909 & 821 & 0.180 \\
\hline Total glucose $(\mathrm{mmol} \times 6 \mathrm{~h} / \mathrm{l})$ & 32.4 & $2 \cdot 8$ & 31.5 & 4.6 & 33.6 & 2.9 & $30 \cdot 8$ & $2 \cdot 3$ & 0.105 \\
\hline
\end{tabular}

Butter-Con, butter-no exercise trial; Olive-Con, olive oil-no exercise trial; Butter-Ex, butter-exercise trial; Olive- Ex, olive oil-exercise trial.

*Value was significantly different between the Olive-Ex and Butter-Con trials $(P=0.022$; Bonferroni post hoc test).

†Bonferroni post hoc tests revealed no significant between-trial differences, but the values tended to be lower in the Olive-Ex trial than in the Butter-Con trial $(P=0 \cdot 118)$.

¥ To obtain insulin in $\mu \mathrm{U} \times 4 \mathrm{~h} / \mathrm{ml}$, divide by 6.08 .

on either the exercise trials or the control trials. These data support a previous investigation where meals high in SFA or MUFA composition induced identical TAG responses in young women, whereas in young men, the MUFA meal elicited significantly higher TAG concentrations than the SFA meal ${ }^{(13)}$. Comparisons of the effects of meal fatty acid composition on pre-menopausal women with men or postmenopausal women may be masked by differences in oestrogen ${ }^{(14)}$, lower abdominal visceral fat ${ }^{(12)}$ and higher adipose tissue lipoprotein lipase activity ${ }^{(33)}$. These differences may explain the lower postprandial lipaemia in pre-menopausal women.

Despite no overall difference between the olive oil and butter meals, we did find a significant difference $3-4 \mathrm{~h}$ into the postprandial period, where the fall in plasma TAG concentrations after consuming the olive oil meals was faster. A previous study ${ }^{(8)}$ in men showed that the size of circulating chylomicrons was higher after an olive oil-mixed meal than after a butter-mixed meal. Moreover, large chylomicrons are preferentially hydrolysed by lipoprotein lipase; hence an olive oil-mixed meal induced the exaggerated increase and faster decline in plasma TAG than a buttermixed meal ${ }^{(13)}$. In the present study, the olive oil meals did not induce greater acute plasma TAG increases compared with the butter meals. Faster declines were observed after the consumption of the olive oil meals in both exercise and control trials, however, supporting the hypothesis that TAG clearance is affected by fatty acid composition. Further support for this hypothesis is provided by others who found that intestinal derived TAG-rich lipoproteins were significantly higher in the late postprandial period after a butter than olive oil meal ${ }^{(6)}$. Mechanistic studies are needed to clarify any plasma TAG-lowering effects by olive oil in young women.

In the present study, acute exercise reduced postprandial TAG concentrations. These results support previous studies which have investigated the effects of acute aerobic exercise on postprandial lipaemia in pre-menopausal women ${ }^{(34,35)}$. Even though exercise duration was shorter in the present study (i.e. $60 \mathrm{~min}$ ) than the previous studies ${ }^{(34,35)}$ (i.e. $90 \mathrm{~min}$ ), thereby eliciting a lower energy expenditure, we still found significant postprandial TAG-lowering effects. Exercise-induced energy expenditure is known to determine the size of any reduction in postprandial lipaemia ${ }^{(16,17)}$.
The reason for the lower plasma TAG concentrations after the olive oil meal with exercise compared with the butter meal without exercise in the present study is unclear. Postprandial plasma insulin concentrations are known to inhibit skeletal-muscle lipoprotein lipase activity ${ }^{(36)}$ reducing TAG clearance. There were no significant differences, however, in the insulin concentrations among the trials. Moreover, some researchers have suggested that there is no relationship between fasting and postprandial TAG and insulin concen-
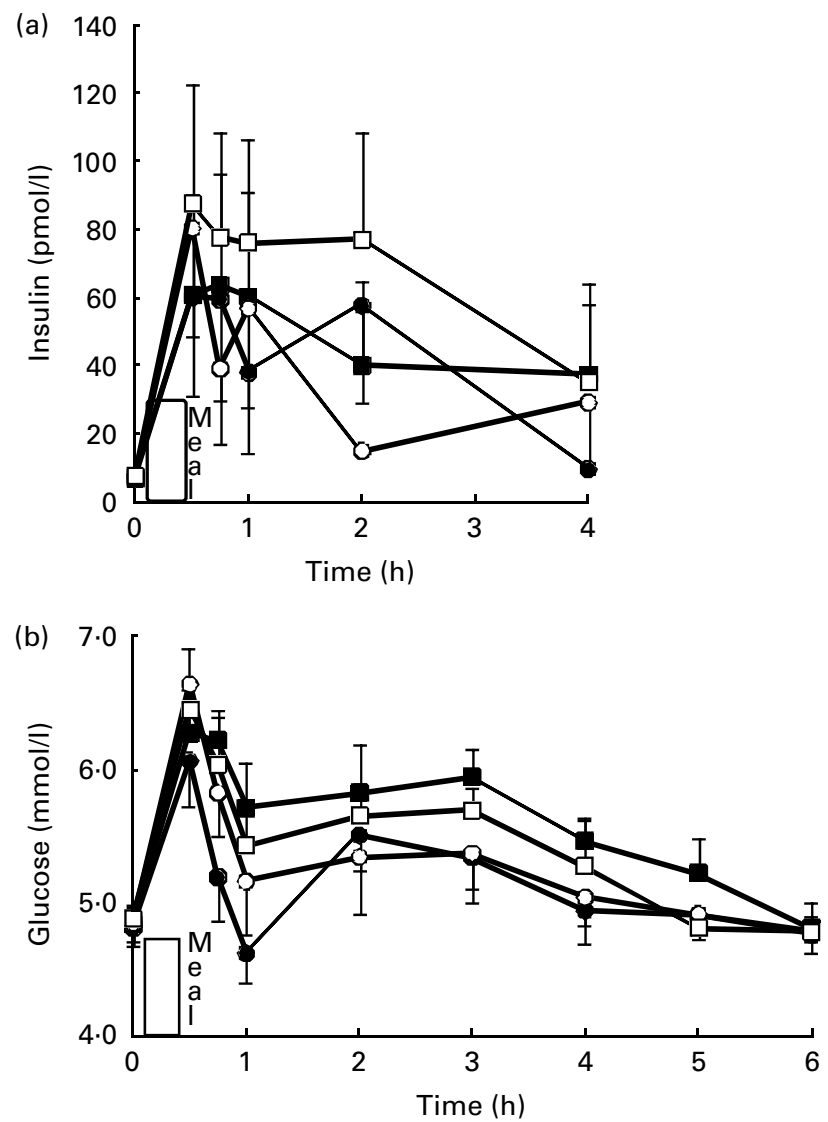

Fig. 3. Postprandial plasma (a) insulin and (b) glucose concentrations in olive oil-exercise trial (- - ), butter-exercise trial (- - ), olive oil-no exercise trial $(-\circ)$ and butter-no exercise trial $(-\square-)$. Values are means $(n 9)$, with standard errors represented by vertical bars. To obtain insulin in $\mu \mathrm{U} / \mathrm{ml}$, divide by 6.08. Main effect of postprandial interval for insulin $\left(F_{(5)}=3.973\right.$, $P=0.005)$; main effect of food for glucose $\left(F_{(1)}=8.8893, P=0.018\right)$; main effect of postprandial interval for glucose $\left(F_{(3.079)}=11.547, P<0.001\right)$. 
trations ${ }^{(37)}$. An alternative explanation for differences in plasma TAG concentrations between the trials is reduced hepatic secretion of $\mathrm{VLDL}^{(38)}$ but the present study was not designed to assess this factor.

Lower HDL-C concentrations, in the fasted or postprandial state, are potentially atherogenic ${ }^{(39)}$. Previous studies ${ }^{(13,40,41)}$ have reported that dietary fatty acid composition influences circulating concentrations of postprandial HDL-C in men. We observed no differences in plasma HDL-C concentrations among the trials. This finding agrees with the results of other studies, which found that postprandial HDL-C concentrations decreased in men ${ }^{(13,40,41)}$ but not in women ${ }^{(13)}$. In the present study, the olive oil and exercise-induced lowering of postprandial TAG in healthy women that we observed did not appear to influence HDL-C.

As previously noted, when meal fatty acid composition is altered, there appears to be little overall impact on postprandial TAG concentrations in young women ${ }^{(13)}$. In response to exercise without replacement of the subsequent energy debt by food intake, women had lower concentrations of insulin and higher concentrations of acylated ghrelin than men ${ }^{(25)}$, both of which would be expected to stimulate energy intake. This suggests that women more effectively defend body fat than men. Thus, an exercise or diet intervention alone may limit beneficial effects on fat metabolism in women. This may lead to a loss of motivation when making lifestyle changes. The present findings are practically important because we demonstrate that a combined intervention of feeding and exercise is effective in reducing postprandial TAG concentrations in young women. Longer-term training interventions in ecologically valid settings are needed to determine whether these behaviours can truly benefit women.

In summary, the present study demonstrated that postprandial plasma TAG concentrations are reduced in young women after $1 \mathrm{~h}$ of moderate to vigorous exercise in combination with the consumption of a high-fat meal containing olive oil instead of butter. These findings suggest that an optimal strategy for young females to reduce postprandial TAG concentrations may be to combine exercise and consumption of monounsaturated rather than saturated fats. Longitudinal studies are required to determine whether this strategy leads to a sustained lowering of postprandial lipaemia.

\section{Acknowledgements}

This study was partly supported by the Mitsukoshi Health and Welfare Foundation. The authors wish to thank all of the volunteers for their participation in this study. C. S. and D. J. S. conceived the study. All authors contributed to the data collection. C. S. and S. F. B. were responsible for the data analysis. C. S. wrote the first draft of the manuscript. All authors were involved in the writing of the manuscript. None of the authors has any conflict of interest with respect to this work.

\section{References}

1. Knoops KT, de Groot LC, Kromhout D, et al. (2004) Mediterranean diet, lifestyle factors, and 10-year mortality in elderly European men and women: the HALE project. JAMA 292, 1433-1439.

2. Covas MI (2007) Benefits of the Mediterranean diet on cardiovascular disease. Future Cardiol 3, 575-578.

3. Covas MI, Konstantinidou V \& Fitó M (2009) Olive oil and cardiovascular health. J Cardiovasc Pharmacol 54, 477-482.

4. Bansal S, Buring JE, Rifai N, et al. (2007) Fasting compared with nonfasting triglycerides and risk of cardiovascular events in women. JAMA 298, 309-316.

5. Nordestgaard BG, Benn M, Schnohr P, et al. (2007) Nonfasting triglycerides and risk of myocardial infarction, ischemic heart disease, and death in men and women. JAMA 298, 299-308.

6. Thomsen C, Rasmussen O, Lousen T, et al. (1999) Differential effects of saturated and monounsaturated fatty acids on postprandial lipemia and incretin responses in healthy subjects. Am J Clin Nutr 69, 1135-1143.

7. Thomsen C, Storm H, Holst JJ, et al. (2003) Differential effects of saturated and monounsaturated fats on postprandial lipemia and glucagon-like peptide 1 responses in patients with type 2 diabetes. Am J Clin Nutr 77, 605-611.

8. Mekki N, Charbonnier M, Borel P, et al. (2002) Butter differs from olive oil and sunflower oil in its effects on postprandial lipemia and triacylglycerol-rich lipoproteins after single mixed meals in healthy young men. J Nutr 132, 3642-3649.

9. Roche HM, Zampelas A, Jackson KG, et al. (1998) The effect of test meal monounsaturated fatty acid:saturated fatty acid ratio on postprandial lipid metabolism. Br J Nutr 79, 419-424.

10. Jackson KG, Robertson MD, Fielding BA, et al. (2002) Olive oil increases the number of triacylglycerol-rich chylomicron particles compared with other oils: an effect retained when a second standard meal is fed. Am J Clin Nutr 76, 942-949.

11. Georgopoulos A \& Rosengard AM (1989) Abnormalities in the metabolism of postprandial and fasting triglyceride-rich lipoprotein subfractions in normal and insulin-dependent diabetic subjects: effects of sex. Metabolism 38, 781-789.

12. Couillard C, Bergeron N, Prud'homme D, et al. (1999) Gender difference in postprandial lipemia: importance of visceral adipose tissue accumulation. Arterioscler Thromb Vasc Biol 19, 2448-2455.

13. Koutsari C, Zagana A, Tzoras I, et al. (2004) Gender influence on plasma triacylglycerol response to meals with different monounsaturated and saturated fatty acid content. Eur J Clin Nutr 58, 495-502

14. van Beek AP, de Ruijter-Heijstek FC, Erkelens DW, et al. (1999) Menopause is associated with reduced protection from postprandial lipemia. Arterioscler Thromb Vasc Biol 19, 2737-2741

15. Petitt DS \& Cureton KJ (2003) Effects of prior exercise on postprandial lipemia: a quantitative review. Metabolism 52, 418-424.

16. Gill JM, Herd SL \& Hardman AE (2002) Moderate exercise and post-prandial metabolism: issues of dose-response. J Sports Sci 20, 961-967.

17. Tsetsonis NV \& Hardman AE (1996) Reduction in postprandial lipemia after walking: influence of exercise intensity. Med Sci Sports Exerc 28, 1235-1242.

18. Hardman AE, Lawrence JE \& Herd SL (1998) Postprandial lipemia in endurance-trained people during a short interruption to training. J Appl Physiol 84, 1895-1901.

19. Herd SL, Hardman AE, Boobis LH, et al. (1998) The effect of 13 weeks of running training followed by $9 \mathrm{~d}$ of detraining on postprandial lipaemia. Br J Nutr 80, 57-66. 
20. Miyashita M, Park J-H, Takahashi M, et al. (2011) Physical activity status and postprandial lipaemia in older adults. Int J Sports Med 32, 829-834.

21. Burns SF, Hardman AE \& Stensel DJ (2009) Brisk walking offsets the increase in postprandial TAG concentrations found when changing to a diet with increased carbohydrate. Br J Nutr 101, 1787-1796.

22. Koutsari C \& Hardman AE (2001) Exercise prevents the augmentation of postprandial lipaemia attributable to a low-fat high-carbohydrate diet. Br J Nutr 86, 197-205.

23. Koutsari C, Karpe F, Humphreys SM, et al. (2001) Exercise prevents the accumulation of triglyceride-rich lipoproteins and their remnants seen when changing to a high-carbohydrate diet. Arterioscler Thromb Vasc Biol 21, 1520-1525.

24. Donnelly JE, Hill JO, Jacobsen DJ, et al. (2003) Effects of a 16-month randomized controlled exercise trial on body weight and composition in young, overweight men and women: the Midwest Exercise Trial. Arch Intern Med 163, 1343-1350.

25. Hagobian TA \& Braun B (2010) Physical activity and hormonal regulation of appetite: sex differences and weight control. Exerc Sport Sci Rev 38, 25-30.

26. Jackson AS \& Pollock ML (1985) Practical assessment of body composition. Physician Sport Med 13, 76-90.

27. Durnin JV \& Womersley J (1974) Body fat assessed from total body density and its estimation form skinfold thickness: measurements on 481 men and women aged between 16 to 72 years. Br J Nutr 3, 77-97.

28. Taylor HL, Buskirk E \& Henschel A (1955) Maximal oxygen intake as an objective measure of cardio-respiratory performance. J Appl Physiol 8, 73-80.

29. Borg GA (1973) Perceived exertion: a note on "history" and methods. Med Sci Sports 5, 90-93.

30. Gill JMR, Malkova D \& Hardman AE (2005) Reproducibility of an oral fat tolerance test is influenced by phase of menstrual cycle. Horm Metab Res 37, 336-341.

31. Dill DB \& Costill DL (1974) Calculation of percentage changes in volumes of blood, plasma, and red cells in dehydration. J Appl Physiol 37, 247-248.
32. Muniyappa R, Lee S, Chen $\mathrm{H}$, et al. (2008) Current approaches for assessing insulin sensitivity and resistance in vivo: advantages, limitations, and appropriate usage. Am J Physiol Endocrinol Metab 294, E15-E26.

33. St-Amand J, Després JP, Lemieux S, et al. (1995) Does lipoprotein or hepatic lipase activity explain the protective lipoprotein profile of premenopausal women? Metabolism 44, 491-498.

34. Tsetsonis NV, Hardman AE \& Mastana SS (1997) Acute effects of exercise on postprandial lipemia: a comparative study in trained and untrained middle-aged women. Am J Clin Nutr 65, 525-533.

35. Maraki M, Magkos F, Christodoulou N, et al. (2010) One day of moderate energy deficit reduces fasting and postprandial triacylglycerolemia in women: the role of calorie restriction and exercise. Clin Nutr 29, 459-463.

36. Kiens B \& Richter EA (1998) Utilization of skeletal muscle triacylglycerol during postexercise recovery in humans. Am J Physiol 275, E332-E337.

37. Gill JM, Herd SL, Tsetsonis NV, et al. (2002) Are the reductions in triacylglycerol and insulin levels after exercise related? Clin Sci (Lond) 102, 223-231.

38. Gill JM, Frayn KN, Wootton SA, et al. (2001) Effects of prior moderate exercise on exogenous and endogenous lipid metabolism and plasma factor VII activity. Clin Sci (Lond) 100, 517-527.

39. Griffin JH, Kojima K, Banka CL, et al. (1999) High-density lipoprotein enhancement of anticoagulant activities of plasma protein $\mathrm{S}$ and activated protein C. J Clin Invest 103, 219-227.

40. Cohn JS (1998) Postprandial lipemia: emerging evidence for atherogenicity of remnant lipoproteins. Can J Cardiol 14, 18B-27B.

41. Tholstrup T, Sandström B, Bysted A, et al. (2001) Effect of 6 dietary fatty acids on the postprandial lipid profile, plasma fatty acids, lipoprotein lipase, and cholesterol ester transfer activities in healthy young men. Am J Clin Nutr 73, 198-208. 